\title{
Em busca do consenso empresarial: a crise do desenvolvimentismo nas páginas da revista Vida Industrial`
}

\author{
Searching for the business consensus: the crisis of the \\ developmentalism on the pages of Vida Industrial magazine
}

\author{
Jean Talvani Costa e Mário Danieli Neto ${ }^{\star \star}$
}

\begin{abstract}
Resumo: Este artigo tem como objetivo a identificação e interpretação dos elementos discursivos mobilizados pelo empresariado industrial de Minas Gerais filiado à Federação das Indústrias do Estado de Minas Gerais (FIEMG), presentes na publicação da revista Vida Industrial entre 1961 e 1964. Consideramos que tais elementos compuseram estratégias que tinham como objetivo estabelecer um consenso de classe e que sua urgência se dava em um quadro de crise econômica, política e social do modelo nacional-desenvolvimentista, sobretudo durante o governo de João Goulart. Ressaltamos as reivindicações da indústria em tempos de crise e a organização da retórica de oposição em um contexto de radicalização política e social.A retórica de exortação à união e coesão de classe buscou atribuir um sentido histórico ao papel "cívico" compreendido pelo empresariado mineiro em relação à nação brasileira.
\end{abstract}

Palavras-chave: Consenso empresarial. FIEMG. Revista Vida Industrial. Nacional-desenvolvimentismo. Governo João Goulart.

Abstract: This article aims to identification and interpretation of discursive elements mobilized by industrial business comunity of Minas Gerais filiated of Federation of Industrials of State of Minas Gerais (FIEMG) throught the Vida Industrial's magazine between 1961 e 1964.We consider that these strategies aimed to establish a class consensus and that there urgency was in the context of the economic, political and social crisis of national-developmentalist model, mainly

\footnotetext{
^ Submissão: 28/01/2020 | Aprovação: 26/11/2020 | DOI: 10.29182/hehe.v24i2.711

$\star \star$ Respectivamente: (1) Licenciado em História pela Universidade Federal de Alfenas, Mestrando em Economia pela Universidade Federal de Alfenas MG, Brasil | E-mail: talvanicosta@gmail.com | ORCID: 0000-0003-2547-4862 | (2) Professor Associado de História do Brasil da Universidade Federal de Alfenas. Instituto de Ciências Humanas e Letras, Departamento de Ciências Humanas, MG, Brasil | E-mail: mariodanielineto1969@gmail.com | ORCID:0000-0003-1078-5625
}

Esta publicação está licenciada sob os termos de Creative Commons Atribuição-Não Comercial 4.0 Internacional 
during the João Goulart's government. We emphasize the industrial's reivindications on the crises times and the organization of oposition rethoric on the political and social radicalization. That rethoric of exhortation to union and class cohesion was justified by an attribution of historical meaning to the "civic" role understood by the Minas Gerais business comunity in relation to the Brazilian nation.

Keywords: Business consensus. FIEMG. Vida Industrial's magazine. National-developmentalist. João Goulart's government.

JEL: N1; N16 


\section{Introdução}

O presente estudo tem por objetivo identificar e refletir sobre as estratégias para a formação de um consenso empresarial mobilizadas por meio do periódico Vida Industrial, órgão oficial da Federação das Indústrias do Estado de Minas Gerais (FIEMG), com ênfase ao período entre 1961 e $1964 .{ }^{1}$ Nossa análise se estrutura a partir da percepção inicial de que a revista, produzida por industriais e para industriais, tem potencialidade enquanto fonte histórica para a compreensão desses atores históricos no que se refere ao período de 1961 - em especial quando do retorno de sua publicação em novembro desse ano - a 1964, com a deposição de João Goulart por meio de um golpe civil-militar. Privilegiamos em nossa análise os editoriais, os artigos e as reportagens.

Essa escolha pelos editoriais, artigos e reportagens se justifica pelo espaço que esses tinham para veicular a posição dos empresários quanto a temas importantes da conjuntura estudada. As reportagens noticiavam sobre novos empreendimentos no estado, bem como políticas econômicas em perspectiva regional.Vale o destaque para a cobertura de dois fóruns políticos realizados em 1963, que tiveram como participantes figuras como Celso Furtado, Magalhães Pinto, Carlos Lacerda, Juscelino Kubitschek e Juarez Távora.Alguns discursos realizados pelo presidente da entidade, Fábio de Araújo Motta, também apareciam, sendo transcritos trechos da fala em eventos empresariais. Os artigos eram menos comuns e inconstantes, mas eram usados para refletir sobre política econômica e seus impactos para os industriais. Os editoriais eram fixos, em todas as edições levantadas eles estavam presentes. Após 1964, eles inclusive vinham assinados por Nansen Araújo, diretor da revista e que viria a ser presidente da Federação em 1984. Em nossa pesquisa, fizemos o levantamento de todas as edições da revista entre novembro de 1961 e abril de 1974, totalizando 128 edições.

Estratégias são mobilizadas em meio a um quadro econômico de desaceleração do crescimento, de estrangulamento pelo endividamento externo e de déficit público. Um quadro político de tensões acirradas, sobretudo após a renúncia de Quadros e a "solução” parlamentarista. Um quadro social conturbado, de movimentos sindicais patronais e operários em atrito e de parcas

\footnotetext{
${ }^{1}$ A edição de fevereiro de 1951 é a primeira edição preservada da revista, mas a sua primeira edição foi veiculada em meados de 1950. Até novembro de 1956, a revista teve uma periodicidade irregular, compreendendo em algumas ocasiões dois meses e em outras oito meses. Sem justificativa oficial, a revista saiu de circulação e voltou a ser veiculada em novembro de 1961, sendo publicada de forma regular e mensal até novembro de 1994.
} 
margens para negociação. Por meio de tal análise historiográfica, também discutimos de que forma e mediante quais condições históricas o empresariado se constituía enquanto um grupo civil fundamental para endossar o entendimento acerca da experiência democrática encerrada em 31 de março de 1964.

Para cumprir seu objetivo interpretativo, este artigo divide-se em três tópicos: o primeiro no qual procuramos fazer uma síntese acerca dos problemas macroeconômicos que caracterizaram a crise dos anos 1960 e suas resultantes em Minas Gerais. No segundo, discutimos os “espaços” de consensos produzidos por meio da revista, de tal maneira que se destacou a relação entre o empresariado e a política econômica. No tópico final, destacamos a "tomada de posição" pelos industriais na revista diante da crise política do governo Goulart, que culminou na sua derrubada.

\section{A crise do desenvolvimentismo}

Em linhas gerais, podemos afirmar que o governo Juscelino Kubitschek promoveu políticas de desenvolvimento a favor da industrialização pesada ${ }^{2}$ no país. Seu projeto de modernização tendia a investir de forma significativa nas áreas até então lacunares da economia nacional, com a ampliação da capacidade de produção industrial nas áreas de energia, construção civil e automobilística (Baer, 1979).

Todavia, o processo de desenvolvimento não ocorreu sem contradições. Embora o país tenha se tornado autônomo em setores estratégicos, o modelo baseado no endividamento externo e na flexibilização da política monetária legou alguns problemas que levaram a uma grave crise nos anos 1960, que - sem sucesso - tiveram de ser enfrentadas pelos governos de Jânio Quadros e de João Goulart.

Durante a fase de crescimento, não houve uma apropriação da renda pelo trabalhador sobre os aumentos na produtividade. Caso da relação salário-consumo, que sofreu um decréscimo de 0,2\% entre 1956 e 1960 (Colistete, 2009).A instabilidade inflacionária verificada durante o período ajuda a compreender mais precisamente a dificuldade no aumento da renda real do tra-

\footnotetext{
${ }^{2}$ Este conceito é defendido por João Manuel Cardoso de Mello (2009). Segundo o autor, entre 1933 e 1955 configurou um tipo de industrialização restringida pela insuficiência técnica e financeira para que se fundamentasse o núcleo da indústria de bens de produção. Enquanto, entre 1956 e 1961, configurou-se a industrialização pesada pela aceleração da capacidade de produtiva do setor de bens de produção e dos bens duráveis de consumo, o que possibilitou um novo padrão de acumulação capitalista.
} 
balhador. Sua evolução anual de 1956 a 1961 foi, respectivamente, de 24,4\%, 7\%, 24,3\%,39,5\%,30,5\% e 47,7\% (Bielschowsky, 2000). Configurava-se assim uma condicionante decisiva para as relações entre empresários e trabalhadores com a crise do início dos anos 1960: o conflito distributivo. Na medida em que empresários demandavam a manutenção de suas margens de lucro e acesso ao crédito, os trabalhadores lutavam pelo aumento real de salário.

Outro problema que crescia em torno das decisões da política econômica era o do endividamento externo, que atingiu o patamar de 3,77 bilhões de dólares em 1960. Mais do que o montante da dívida, seu principal problema consistia em seu perfil de curto prazo, cujos haveres deveriam ser saldados em até três anos, o que comprometeria o crescimento econômico se não houvesse auxílio internacional (Loureiro, 2012). O sucesso das negociações com o capital externo estava vinculado, desse modo, às taxas de crescimento que o produto interno bruto pudesse atingir, na medida em que pudesse desembolsar tais pagamentos conforme conseguisse ampliar sua poupança interna.Todavia, as ameaças ao equilíbrio da balança de pagamentos e o déficit no setor público tornavam-se obstáculos para que tais obrigações financeiras externas fossem cumpridas com menor estrangulamento interno.

Em suma, podemos considerar que o país que Juscelino Kubitschek passava a Jânio Quadros na cerimônia de posse em 31 de janeiro de 1961 em Brasília, na nova capital inaugurada em abril do ano anterior, apresentava-se mais modernizado, diversificado produtivamente e com setores industriais plenamente constituídos, como o setor metalúrgico, automobilístico e químico, tendo atingido ligações infraestruturais entre regiões que antes estavam distantes do acesso aos transportes, além de uma capacidade enérgica muito maior. Por outro lado, não conseguiu estabelecer o mesmo desenvolvimento econômico no campo do desenvolvimento social, além de não superar problemas macroeconômicos que vieram a comprometer fortemente a continuidade do projeto desenvolvimentista.

Se o período que coincide com a presidência de Juscelino Kubitschek pode ser considerado o auge do desenvolvimentismo, o período subsequente, entre 1961 e 1964, foi caracterizado pela instabilidade política, pela mobilização acerca das reformas sociais, grandes dificuldades monetárias, financeiras, cambiais e, a partir de 1962, por um acentuado declínio das taxas de crescimento. Com isso, o projeto de industrialização planejada, principal orientador do pensamento econômico dos desenvolvimentistas, deu lugar a problemas conjunturais pela pressão inflacionária e pelo desequilíbrio do balanço de 
pagamentos, assim como às soluções de curto prazo e à inserção dos debates acerca das reformas sociais - principalmente a agrária - e as reformas institucionais - como a bancária e administrativa (Bielschowsky, 2000).

A desaceleração do crescimento no período, causada pelo aumento da capacidade ociosa após a maturação dos investimentos, obrigava o empresariado a tomar decisões objetivando a acumulação de capital, ocasionando a diminuição no gasto privado, assim como a redução do número de empregos criados. A partir desse primeiro entrave, podemos salientar que se, de um lado, o empresariado precisava acumular capital mediante corte de gastos, por outro, os trabalhadores procuraram defender sua renda real exigindo aumento nos salários. O que configurava um conflito distributivo entre empresários e trabalhadores (Bastos, 2011).

Ao passo que o Plano de Metas acumulou queda de 20\% nas exportações, levada sobretudo pela queda do preço do café, as importações de insumos básicos e bens de capital puderam ser financiadas pelo influxo de investimentos externos e créditos comerciais: na conclusão do Plano, as remessas de lucro, juros e dividendos pressionavam remessas cambiais e a taxa de câmbio do cruzeiro, gerando o desequilíbrio no balanço de pagamentos (Bastos, 2011).

A aceleração inflacionária apresentava-se como outro problema, dado que o déficit público e o estrangulamento nas ofertas eram os seus grandes motivos. $\mathrm{O}$ processo de diversificação produtiva era barrado por problemas financeiros e tecnológicos. A inflação corroía tributos, o que fazia com que os contribuintes atrasassem o recolhimento, assim a desaceleração do crescimento era proporcional à arrecadação tributária. Desse modo, além da alta geral de preços, o déficit fiscal era outra preocupação quanto ao planejamento econômico (Bastos, 2011).

Tomando o caso mineiro de modo mais específico, os problemas de capital social básico, como energia e transportes, puderam ser expandidos, o que poderia diversificar sua produção e consolidar a estrutura de seu parque industrial ao final da década de 1950. De acordo com Eakin, Minas Gerais havia construído ao longo das décadas de 1940 e 1950 uma base industrial fundada no setor minerador, o que favoreceu um crescimento da atividade industrial. Segundo o autor, ocorreu nesse período a inserção de Minas Gerais na primeira grande onda de crescimento industrial do país durante a década de 1950 (Eakin, 2002).

Com o advento da crise econômica e com as incertezas na direção política da primeira metade da década de 1960, houve uma retração dos 
investimentos e um retardamento da expectativa da expansão do parque industrial no Estado (Diniz, 1981). Nesse sentido, setores de bens de consumo não duráveis sofreram com a descapitalização, o que ensejou decisões de fusão de empresas em um momento de falência de muitos desses empreendimentos, sobretudo no gênero alimentício. Por outro lado, o setor de bens intermediários, como a metalurgia e a indústria química, cresceu no nível da participação no produto interno do Estado. A tendência geral verificada foi a de um acelerado processo de concentração de capital (Diniz, 1981).

Em linhas gerais, essa configuração econômica que o Brasil enfrentava no início dos anos 1960 ajuda a compreender não só os desequilíbrios, como o malogro do programa desenvolvimentista, mas também como a crise do desenvolvimento possuiu laços estritos com a crise social e política que demarcou o período, podendo-se apontar tal crise como um dos motivos para a tomada de posição do empresariado em favor do Golpe de 1964.

Enquanto isso, a industrialização planejada ocupava um papel central nas formulações desenvolvimentistas. O pensamento econômico desses economistas tornou-se a retórica e a prática do próprio processo de modernização do país, que gozou de seu auge sob os anos do governo Juscelino Kubitschek ente 1956 e 1961. Todavia, o clima de instabilidade política, econômica e social do início dos anos 1960, ocasionou um deslocamento das preocupações dos teóricos do desenvolvimento para soluções de curto prazo, exigidas não só pelas condições macroeconômicas observadas, mas também pelos grupos de pressão que demandavam a manutenção de interesses.

Nesse sentido, a natureza econômica do desenvolvimentismo não pode ser entendida em sua complexidade se não nos atermos à natureza social e política que caracterizou os processos verificados entre 1961 e 1964. Desse modo, a disputa pela industrialização em quadro de crise do desenvolvimento nacional é delimitada, em nosso estudo, a partir da manutenção de um consenso de classe empresarial.

\section{Política econômica e "reivindicações da indústria" em tempos de crise}

Jânio Quadros assumiu a presidência da república em 31 de janeiro de 1961 com um feroz discurso em relação ao legado econômico da gestão juscelinista, reclamando da desaceleração do crescimento, do déficit público e dos custos exaustivos da dívida externa.Já em março de 1961, Jânio Quadros 
pôs em prática a primeira e principal medida econômica de sua curta passagem pela presidência: a instrução 204 da Superintendência da Moeda e do Crédito (SUMOC), ${ }^{3}$ que visava à flexibilização da política cambial.

Em abril de 1961, sete meses antes da retomada da publicação da revista Vida Industrial, os sindicatos patronais mineiros formularam um documento de reivindicações para o presidente Jânio Quadros. Compunham esse documento as seguintes instituições e seus respectivos líderes: Associação Comercial de Minas (Euler Marques Andrade), Centro das Indústrias da Cidade Industrial (Jonas Barcellos Corrêa), Clube dos Diretores Lojistas de Belo Horizonte (Oscar Nicolai), Federação das Associações Rurais do Estado de Minas Gerais (Josaphat Macedo), Federação do Comércio do Estado de Minas Gerais (Nylton Moreira Velloso), Federação das Indústrias do Estado de Minas Gerais (Fábio de Araújo Motta), Sociedade Mineira de Agricultura (Dirceu Duarte Braga), Sociedade Mineira de Engenheiros (Vicente Assupção) e União dos Varejistas de Minas Gerais (Synval Ladeira Neves). ${ }^{4}$

Como é perceptível, a lista de empresários e instituições era numerosa, o que mostra uma primeira questão: qual o grau de coesão possível entre tantas entidades patronais para a formulação de um documento reivindicatório? Para compreendermos essa questão, precisamos, antes mesmo de destacar as sumárias reivindicações, dar relevo às condições de sua formulação. Logo no primeiro parágrafo, após a citação às instituições que compõem o documento, complementa-se: "após sinalizar detidamente, por meio de seus Departamentos Técnicos, suas diretorias e Conselhos, a Instrução nº 204 da 'SUMOC', compreendendo os patrióticos objetivos que a inspiraram vem hipotecar ao governo de V. Exa. construtiva solidariedade". Fica indicado, inclusive como instrumento de legitimação das reivindicações, o papel técnico e burocrático do documento. De modo que sua consistência não seria garantida apenas pelo montante dos participantes, mas pela solidez e embasamento garantidos pelas instâncias de estudo e regulamentação dos sindicatos patronais.

Em suma, as reivindicações presentes no documento caminhavam em três direções: a preocupação com o desenvolvimento regional, integração internacional e redução do déficit público. A primeira, e mais aludida, apon-

\footnotetext{
${ }^{3}$ Anteriormente à fundação do Banco Central na gestão Bulhões e Campos durante o governo Castelo Branco, a SUMOC era o órgão responsável pelas políticas creditícias e monetárias.

${ }^{4}$ Reivindicação das Classes produtoras de Minas Gerais ao Exmo. Sr. Dr. Jânio da Silva Quadros, 20 de abril de 1961 (Centro de Memória do Sistema FIEMG).
} 
tava para a necessidade de descentralização da política bancária para os bancos estaduais, servindo de suporte às medidas de desenvolvimento industrial e agrícola por meio da desburocratização para os critérios de empréstimos.

A integração internacional era vista como útil por dois motivos: a garantia da expansão de mercados exportadores - pela estruturação de escritórios comerciais para a promoção de vendas no exterior - e a abertura para financiamentos e empréstimos garantidas pela nova política cambial. Por fim, a redução do déficit público, que era um tema extremamente caro nesse contexto, ocupava um destaque simples: "a redução das despesas do custeio do governo e a disciplinação das despesas de investimento". A primeira, reconhecida na obrigação governamental em racionalizar seus aparelhos, enquanto a segunda estava a serviço da descentralização dos financiamentos, como se discutia em outros pontos da reivindicação.

Ainda que não se trate de um documento veiculado na revista Vida Industrial, mas sim de um conjunto de reivindicações patronais entregues naquele momento ao então presidente Jânio Quadros, cumpre destacar sua importância, pois permite mapear a percepção e a participação empresarial em um período delicado para a economia do país.

A retomada da publicação da revista Vida Industrial ocorreu em novembro de 1961 pela direção eleita pela entidade em janeiro daquele ano. A plurivocidade presente nas fontes leva em conta para quem elas se dirigem e quais intenções podem ser localizadas por meio do corpo do texto.

Nas palavras de Fábio de Araújo Motta - presidente da FIEMG entre 1960 e 1983 - sobre a revista:

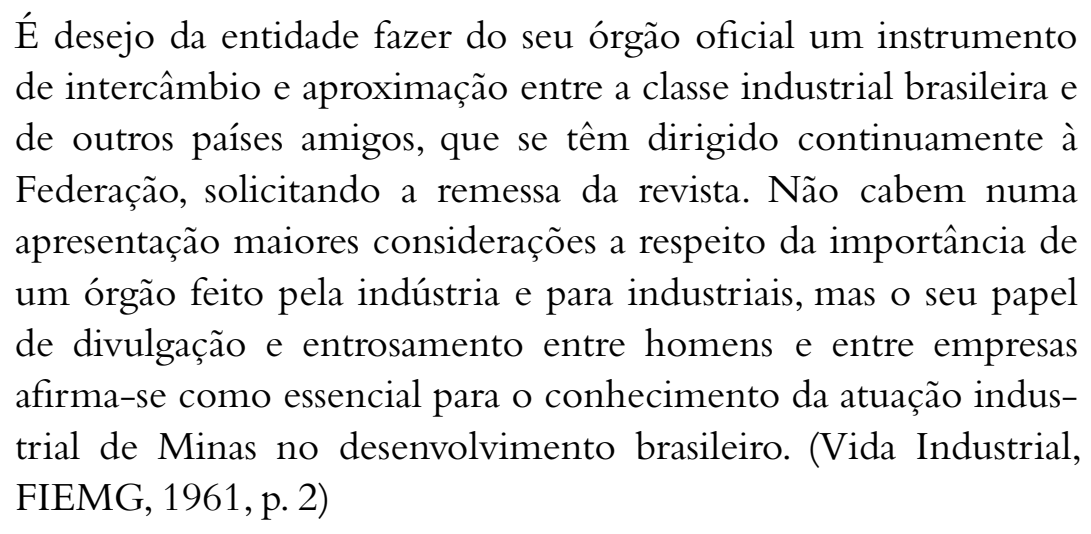

"Divulgação" "entrosamento" e “desenvolvimento" são os termos que melhor podem explicar os objetivos iniciais da publicação, compreendendo o papel do periódico para o diálogo entre a classe, que vê na atuação industrial 
um caminho possível para o desenvolvimento, que necessita de um veículo que "entrose" a classe para objetivos semelhantes e que se utilizará de uma revista para que isto se concretize. $\mathrm{O}$ consenso desejado pelo editorial pode ser tomado como premissa da FIEMG na atuação em setores da vida política brasileira, no que toca, principalmente, à relação com as instâncias do Estado.

Nesse sentido, as entidades empresariais atuaram como meio de um "projeto de classe que buscava estabelecer a indústria como a "redenção da Nação", numa prática consistente com a condição de uma burguesia criadora e criatura de um capitalismo retardatário e dependente no país" (DELGADO, 1997, p. 19). A atuação e formação de um consenso diz respeito à definição de interesses e uma racionalização nas práticas junto ao governo, aos trabalhadores e ao capital estrangeiro. Neste viés, a revista se propõe a condensar alguns dos temas de interesse industrial.

No esforço de compreender o entrosamento entre as elites regionais e seu respectivo desenvolvimento econômico, Otavio Soares Dulci (1999) aponta que a existência e funcionamento das entidades dos grupos patronais tomaram uma grande importância pelos critérios para a escolha de representantes de classe na Constituinte de 1934, pela qual só teriam representatividade as instituições formalizadas. A esse passo, a Federação das Indústrias foi montada como um órgão sindical, preparando o empresariado para conflitos com outros setores, como o sindicalismo operário (Dulci, 1999). Portanto, depreendemos dessas considerações que a Federação se projetava de forma nacional ou regional, na medida em que estivesse organizada e com interesses sintonizados.

O que demonstraremos, nesse primeiro momento, é o papel fundamental do corpo técnico ligado à Federação para as relações internas e externas ao empresariado. Em pelo menos três momentos identificamos, por meio da revista, o papel do Departamento de Estudos Econômicos da FIEMG. São estes: a criação do Banco de Desenvolvimento de Minas Gerais (BDMG), o Fundo do Minério e a instalação da refinaria Gabriel Passos da Petrobrás em Betim.

Convencionou-se, pela literatura interessada no tema, tratar esse corpo técnico por "tecnocracia", haja vista sua relação com os aparelhos de governo estaduais e nacionais. O Departamento de Estudos Econômicos da FIEMG, surgido em 1948, teve espaço nos projetos da Usiminas e da Açominas, estimulou a criação de um banco regional de desenvolvimento e a implementação de uma refinaria da Petrobrás, que se concretizaram com a criação do 
BDMG em 1962 e com a construção da Refinaria Gabriel Passos em Betim (Dulci, 1999).

A tecnocracia mineira surgiu no bojo das transformações da economia brasileira na década de 1930 e teve participação importante em momentos decisivos. Em um primeiro momento, de mudança ocorrida no padrão de acumulação agrário-exportador para urbano-industrial, impondo a necessidade de uma orientação para a ação do Estado (Diniz, 1981). Conforme apontou Eakin, o esforço da classe empresarial durante esse primeiro período, favoreceu a criação de uma infraestrutura básica e de financiamento com participação de capital público e privado, o que foi fundamental para consolidar um novo modelo de empreendimento industrial no pós-guerra (Eakin, 2001). Um segundo momento veio nos anos 1950, durante a gestão de Juscelino Kubitschek em Minas Gerais, com a fundação das Centrais Elétricas de Minas Gerais (CEMIG) e a ascensão dos engenheiros a assumirem postos na administração pública estadual e federal (Diniz, 1981). Na análise de Eakin, os anos 1950 marcaram um período de entrada maciça de recursos públicos (via Estado e esfera federal), além de capital externo no setor industrial mineiro. Segundo esse autor, tal fato deveu-se ao esforço e aprendizado do empresariado industrial nas décadas anteriores, que haviam percebido que sem o aporte de investimentos públicos, o desejado desenvolvimento industrial do Estado seria inviável (Eakin, 2001, p. 89). O terceiro momento coincide justamente com o momento de nossa análise, a partir de 1961, com a criação do Banco do Desenvolvimento de Minas Gerais (BDMG), ascendendo o chamado grupo dos economistas (Diniz, 1981).

O Banco do Desenvolvimento de Minas Gerais foi tema de um artigo escrito pelo engenheiro José Vianna de Assis, intitulado "Banco do Desenvolvimento, justificativa e repercussão na economia mineira", na edição de novembro de 1961. O articulista dá ênfase principalmente à oferta de crédito para a implementação de maquinário produtivo para os setores industriais e agrícolas, bem como à defesa de que sua atuação viesse a suprir insuficiências do setor de infraestrutura, energia e comunicação (Vianna, 1961).

A “justificativa" se embasava no fato de que a pequena e média indústria mineira não possuía suporte financeiro suficiente para sua instalação e existência de novos empreendimentos. Àquela altura, havia duas instituições de financiamento à indústria, o Banco do Brasil e o Banco Nacional de Desenvolvimento Econômico (BNDE). O primeiro financiava indústrias apenas nos três primeiros anos de financiamento, enquanto o segundo atendia à 
infraestrutura e aos grandes projetos industriais. A proposição era da existência desse banco regional com um capital inicial de dois bilhões de cruzeiros que facilitasse os financiamentos e encaminhasse o aval de contratação de crédito no exterior para empreendimentos industriais e agrários (Assis, 1961).

A FIEMG lançava mão, portanto, de um projeto de descentralização creditícia até então exclusiva aos órgãos nacionais com o Banco do Brasil e o BNDE. Empreendia-se, também, um esforço de garantir a estabilidade e continuidade de empreendimentos no estado a partir de políticas de médio e longo prazo.

Clélio Campolina Diniz (1981) notou que a criação do BDMG vinha sendo planejada desde os anos 1950. Para isso, a equipe técnica à qual fizemos menção conseguiu encaminhar um projeto ainda em 1957, com o apoio do deputado Saulo Diniz, mas sem aprovação. Todavia, com o sucesso da instalação do BDMG, a equipe que assessorava o deputado na formulação do projeto conseguiu manter sua influência no momento de sua instalação bem-sucedida. Faziam parte da equipe:JoséVianna de Assis, Jaime de Andrade Peconick, Silviano Cançado Azevedo e Roberto Teixeira Campos, todos economistas do Departamento de Estudos Econômicos da Federação (Diniz, 1981).

Na edição de dezembro de 1961, a Vida Industrial dava destaque ao Encontro dos Governadores com o então presidente João Goulart, salientando as reivindicações da indústria. Momento oportuno, mais uma vez, para a participação ativa do Departamento de Estudos Econômicos da FIEMG.É oportuno também, de nossa parte, apontar algumas especificidades que marcaram a conjuntura do evento. A justificativa empreendida, logo de início, versava sobre o atraso de um mês para a realização do encontro (Vida Industrial, FIEMG, 1961).A motivação para esse atraso era a renúncia do presidente Jânio Quadros em 25 de agosto daquele ano. ${ }^{5}$

Em meio à enorme tensão causada por tal decisão, a solução parlamentarista acabou sendo a intermediária entre os setores civis e militares. João Goulart a aceitou a contragosto, pois acabou convencido porTancredo Neves pelo fato de que, segundo ele, poderia haver, do contrário, uma guerra civil no país. O Congresso acabou aprovando a medida por 233 votos a 55. João

\footnotetext{
${ }^{5}$ Segundo Jorge Ferreira (2011), o motivo mais aceito para a renúncia de Jânio seria sua intenção de dar um golpe de Estado. Com o conflito entre o Congresso e a presidência por conta dos inquéritos sobre casos de corrupção, sua ideia era conseguir o apoio dos ministros militares para seu retorno ao poder, dado, inclusive, à rejeição pelo vice-presidente João Goulart (Ferreira, 2011).
} 
Goulart tomou posse com essas condições em 7 de setembro de 1961 (Ferreira, 2011).

Com a realização, em novembro de 1961, do Encontro dos Governadores, a indústria mineira, representada pela Federação, entregou uma série de reivindicações. Vale o destaque para a recorrência e a ênfase à política creditícia novamente afirmada no documento entregue ao presidente João Goulart: a descentralização bancária em unidades regionais, a desburocratização dos meios de financiamento e o incentivo à indústria e à agropecuária (Vida Industrial, FIEMG, 1961). As características do documento seguiam a linha de uma produção muito técnica formulada pelos economistas do Departamento de Estudos Econômicos, seguindo o mesmo formato que destacamos nas reivindicações ligadas à Instrução n 204 da SUMOC, bem como à fundação do BDMG. Outras duas reivindicações inéditas são apresentadas no documento: as transferências para o Estado da Companhia Siderúrgica Nacional e da Companhia de Aços Especiais Itabira (ACESITA) e da instituição do Fundo do Minério.

A intenção em relação à primeira era interiorizar as instalações da Companhia Siderúrgica Nacional para a região do Vale do Paraopeba, próximo ao município de Conselheiro Lafaiete, de modo que ela atuasse na produção de aço em parceria com a empresa Mannesmann e com suporte enérgico oferecido pela CEMIG, a partir de estudos realizados pelos departamentos técnicos das entidades patronais, bem como do Conselho de Economia e Administração do governo de Minas Gerais (Vida Industrial, FIEMG, 1961).

Em relação à instituição do Fundo do Minério, sua proposição era resultante da proposta de alocação das instalações da CSN apontada anteriormente.A intenção era que os recursos obtidos pelo empreendimento compusessem um fundo que pudesse ser administrado por estabelecimentos de créditos, sob a administração estatal por meio do banco do desenvolvimento estadual (Vida Industrial, FIEMG, 1961).

No editorial, além de apontar para o esforço de consolidação do parque industrial mineiro, a justificativa designava o esforço de Minas Gerais em superar o "semicolonialismo" de algumas de suas regiões. A ideia empregada tende a dar relevo a uma característica atrofiada da economia estadual que deveria expandir-se, na medida em que essa via seria concretizada pelos "caminhos da industrialização" (Vida Industrial, FIEMG, 1961, p. 52).

O papel do Departamento de Estudos Econômicos da FIEMG mais uma vez apareceu no editorial da edição de novembro de 1962 . O sucesso 
da instalação da refinaria de Gabriel Passos, diferentemente da linguagem técnica dos artigos e documentos que salientamos até aqui, teve uma natureza muito mais efusiva e comemorativa, aludindo o papel da tecnocracia ligada à FIEMG, que, por meio de sua revista, engajava-se na luta pelo desenvolvimento e progresso do Estado, "acompanhando o desenrolar das obras". Em especial, a publicação exaltava a diligência do engenheiro Maurício Silva, “jovem, entusiasta, eficiente” (Vida Industrial, FIEMG, 1962, p. 2).

A continuidade estabelecida entre os trechos destacados e a discussão que desenvolvemos até aqui indica o reconhecimento da importância da elite técnica ligada à FIEMG para os rumos da própria instituição. O intuito desse grupo era harmonizar o projeto econômico para o Estado com os interesses empresariais, com a defesa do desenvolvimento industrial e com a própria ação supletiva reconhecida nos aparelhos de Estado.

O artigo "Planejamento, políticas partidárias e administração" trazia a discussão sobre a importância do planejamento descentralizado por meio de instituições regionais. Guilherme Vivacqua, um dos articulistas da redação, escreve que

Cada governante sempre se propõe a executar o seu próprio programa e muitas vezes em detrimento de projetos em curso. Os esforços tornam-se individuais e isolados. Daí a necessidade imperativa de órgãos de planejamento regionais, compostos com equipes essencialmente técnicas, esboçando projetos de desenvolvimento a longo prazo. Não é admissível altercações dos mesmos. O planejamento deve ser global e não parcial como se tem feito. Nota-se, ainda, a concentração de recurso em áreas politicamente fortes, estimulando o círculo vicioso da pobreza nas economias regionais e municipais, acentuando dia a dia os desníveis entre elas. Por outro lado, ainda agora, com o Plano Trienal vemos a necessidade imperativa de órgãos de planejamento regionais, que constituiriam a pedra angular de melhor entrosamento dos trabalhos. É uma lacuna incompreensível. (Vivacqua, 1963, p. 17)

Chama-se a atenção, mais uma vez, para o papel articulado entre programas de investimentos estatais - vide o Plano Trienal - e a organização nas esferas regionais de instituições capazes de racionalizar a política de desenvolvimento, de tal maneira que integre o papel privado nesse processo. Nesse sentido, a revista enfatiza a importância de um maior entrosamento entre as proposições do governo federal e as demandas regionais, em particular, no tocante ao desenvolvimento industrial. Ressalte-se a crítica ao Plano Trienal 
feita pelo articulista, ao levantar justamente a falta de conexões entre este e o que chamou de "pobreza" em nível regional. Mais uma vez, a publicação destaca a necessidade de corpos técnicos à frente desse esforço de articulação entre projetos econômicos de caráter nacional.

Aspectos como esses da relação entre empresariado e governo são fundamentais para a compreensão da relação dos postulados defendidos pelos industriais mineiros com a concepção de desenvolvimento defendida pelo programa de planejamento do governo João Goulart, formulado ainda sob o regime parlamentarista e instrumento do retorno ao presidencialismo em 1963. ${ }^{6}$ Para relacionarmos melhor tais sujeitos, é preciso que tratemos de alguns elementos políticos da conjuntura de crise do desenvolvimentismo.

No início dos anos 1960, os grupos de pressão aumentavam o quadro de tensões sociais: de um lado, o Comando Geral dos Trabalhadores (CGT) que ameaçava deflagrar uma greve geral, caso os aumentos salariais não acontecessem. De outro lado, os patrões diziam que não podiam arcar com os aumentos e com o recém-criado $13^{\circ}$ salário (Ferreira, 2011).

João Goulart assumiu a presidência diante de um impasse político no qual, em um primeiro momento, não pôde exercer plenos poderes de presidente, diante da crise política instaurada após a renúncia de Jânio Quadros, e para o qual o Congresso optou por uma solução parlamentarista. No campo econômico, Goulart se via premido pelos problemas macroeconômicos herdados do período JK.

Diante disso, em 6 de janeiro de 1963, aconteceria o plebiscito para a escolha entre presidencialismo ou parlamentarismo: João Goulart precisava de uma bandeira forte. Assim, em setembro de 1962, criou a pasta do planejamento, que fazia parte do Ministério da Fazenda, então sob o comando de San Tiago Dantas. Essa pasta seria liderada pelo superintendente geral da Superintendência de Desenvolvimento do Nordeste (Sudene), o economista Celso Furtado (Ferreira, 2011, p. 323). Seriam três meses para a elaboração do Plano Trienal de Desenvolvimento Econômico e Social, que deveria ser implementado ao longo de três anos, 1963 a 1965. João Goulart anunciou o Plano Trienal na noite do dia 31 de dezembro de 1962 no programa $A$ voz do Brasil.Em suma, o Plano era apresentado como um programa de estabilização

\footnotetext{
${ }^{6} \mathrm{Na}$ leitura de Argelina Figueiredo, o Plano Trienal visava a um duplo objetivo:"de um lado, obter o apoio político dos grupos conservadores e da opinião pública em um momento de transição para o regime presidencialista; de outro, procurava ganhar a confiança dos credores externo, em especial os norte-americanos" (Figueiredo, 1993 apud Ferreira, 2011, p. 327).
} 
econômica de médio a longo prazo, tendo em perspectiva a redução gradual da inflação, um estímulo gradual no salário e reformas estruturais, como a reforma agrária e a reforma bancária, as quais Furtado acreditava que levariam o Brasil a um novo ciclo de desenvolvimento (Ferreira, 2011, p. 327).

Os objetivos gerais do Plano podem ser agrupados em dois sentidos, segundo consta da sua introdução formulada por Celso Furtado: medidas ligadas à orientação no processo de formação de capital e compatibilização da direção dos investimentos com a poupança interna disponível (Brasil, 2011, p. 44).

O Plano Trienal, como um programa heterodoxo com o objetivo principal de dar estabilidade econômica, dispunha de medidas que impunham restrições tanto aos empresários quanto aos trabalhadores: os primeiros em relação ao lucro e ao crédito, e os segundos em relação ao aumento dos salários, que deveriam, a partir da implementação do Plano, evoluir em acordo com o crescimento do produto interno e com a inflação (Loureiro, 2010). Porém, o plano também concebia ações de caráter estrutural, que permitissem a retomada do crescimento econômico e melhor distribuição de renda.

Desse modo, vale refletir sobre a maneira como o empresariado representado pela revista Vida Industrial passou a analisar os possíveis efeitos do Plano Trienal na economia, em especial nos aspectos que diziam respeito diretamente aos problemas distributivos que a sociedade enfrentaria com a implementação da nova política econômica. Como argumenta Ignácio Delgado, o empresariado possuía menos potencialidade em estabelecer laços hegemônicos com movimentos operários e trabalhadores da área de serviços se comparado aos laços que o Estado pode consolidar. Nesse sentido, a presença de elementos redistributivos consiste em um sinal de alerta para a classe, que vê políticas de massa presentes na gerência de aparelhos estatais (Delgado, 1997).

Esse alerta incide diretamente sobre as duas figuras centrais desse contexto: João Goulart e Celso Furtado. O primeiro já tinha a desconfiança do empresariado desde a sua passagem pelo Ministério do Trabalho no governo de Getúlio Vargas, quando decretou um aumento salarial de 100\%, e em um segundo momento, quando em dezembro de 1962 instituiu o $13^{\circ}$ salário (Loureiro, 2010, p. 116).

Essa forma de compreender os entraves para o desenvolvimento e suas possíveis soluções emergiram junto ao Plano formulado nos meses finais de 1962. Além de fazer um mapeamento amplo das condições de desenvolvimento nas diversas regiões do país e discutir as potencialidades da indústria brasi- 
leira, da infraestrutura e do setor agrícola, o programa se propunha a aperfeiçoar a saúde e a educação, e dispunha ao fim as reformas de base capazes de levar o Brasil a um novo ciclo de desenvolvimento (Brasil, 2011, p. 43-44). E a questão apontada pelo empresariado é justamente a de rejeição a um programa redistributivo, pois esse grupo fundamenta sua posição em um discurso de liderança em um processo de desenvolvimento nacional estritamente ligado à industrialização como redenção da Nação. Assim, a distribuição dos benefícios do desenvolvimento econômico está subordinada à modernização econômica do Brasil (Delgado, 1997).

Traduzindo essas posições para o campo de disputas no contexto da execução do Plano, compreendemos que houve, antes que uma rejeição ao programa em si, uma desconfiança sobre que projeto estava representado em João Goulart e Celso Furtado, no tocante ao papel dos aparelhos de Estado na política redistributiva, formando laços com os trabalhadores.

O Plano Trienal foi debatido no decorrer do primeiro semestre de 1963 no Fórum Político em Defesa da Livre Iniciativa - organizado pela FIEMG e pela Associação Mineira de Imprensa -, realizado entre janeiro e maio daquele ano, e que teve como tema central "Desenvolvimento econômico com justiça social sob o regime da livre iniciativa", contando com a presença de representantes empresariais, políticos, sindicais e estudantis (Vida Industrial, FIEMG, 1963).

Destacamos em primeiro lugar a presença de Celso Furtado, reportada na edição de abril/julho de 1963 com o título "Plano Trienal não é revolucionário nem audacioso". Em apresentação,

A visita do Ministro Celso Furtado a M. Gerais constituiu um dos pontos de interesse do Fórum Político em face das controvérsias na interpretação do Plano Trienal. Com a opinião dividida entre seus afirmadores e negadores, a palavra do Ministro veio tornar claro o que estava sendo interpretado de maneira diferente e ainda mostrar aspectos relacionados com sua aplicação como medida de combate à inflação. (Vida Industrial, FIEMG, 1963, p. 6)

O trecho deixa bem claro que a visita de Celso Furtado ao Fórum já tinha a intenção de confrontar uma visão negativa sobre as propostas do programa tomada pelo empresariado, pois logo no início enfatiza que a presença de Furtado no evento objetivava, sobretudo, mostrar que as críticas feitas ao plano por parte do empresariado não eram pertinentes.A reportagem da revista ainda explicita as divisões existentes dentro do próprio núcleo 
dirigente quanto à eficácia das medidas econômicas que o plano preconizava. De todo modo, o ministro da recém-criada pasta do Planejamento, procurava dissuadir a resistência da classe empresarial em relação ao Plano Trienal, negando que este pretendia adotar um direcionamento visto por alguns setores da economia como "revolucionário", palavra que, à época, acabava por acirrar uma nítida polarização ideológica. Desse modo, percebe-se o aspecto de negação que aparece na fala atribuída ao ministro quando enfatiza que

O Plano Trienal nada encerra de "revolucionário" nem de "audacioso", eis que se inspira na mais desapaixonada realidade nacional, suas diretrizes econômicas constituem adaptações às convenções de uma política como que tradicional. Acentuou que, ao início da elaboração do Plano, teve certas perplexidades, eis que, nada encontrou de objetivo, no terreno governamental, no sentido de uma infraestrutura que correspondesse aos anseios das populações, para um início de partida. (Vida Industrial, FIEMG, 1963, p. 6)

A negação de que existam objetivos "revolucionários" ou "audaciosos" quanto ao Plano pode nos auxiliar a indicar a posição dos interlocutores de Furtado àquela altura, em que é tomada a posição de rejeitar os adjetivos empregados diante de um programa heterodoxo e com questões estruturais e reformistas. Com essa postura, insiste, em outro momento, que "não se considera um político porque não está filiado a nenhuma corrente política nem a qualquer grupo político". Em que pese as considerações que fizemos aqui, superar a interpretação antecipada e superficial do empresariado consistiu na primeira estratégia de Celso Furtado em dialogar sobre o Plano.

Sua segunda atitude é a defender o caráter restritivo aos ganhos reais em um primeiro momento para que as condições de crescimento e de controle da aceleração inflacionária fossem possíveis:

O Ministro sustentou a tese de que as críticas inconsistentes são um desserviço ao país e que, em 1964 e 1965 haveremos de manter uma taxa de crescimento de $7 \%$, mas tal não seria possível dentro dos esquemas de financiamento até então adotados. (Vida Industrial, FIEMG, 1963, p. 6)

O ministro muito provavelmente se referia à política de restrição do crédito tomada pelo Plano Trienal, medida tomada para diminuição do déficit público, um dos principais problemas econômicos na primeira metade da década de 1960, como apontamos anteriormente. 
Ao fim de sua participação do Fórum, Furtado pondera sobre o conflito distributivo entre empresários e trabalhadores, observando o quanto esse aspecto prejudicava na implementação de medidas econômicas: "O Ministro Celso Furtado fez uma exortação à consciência nacional no sentido de uma maior harmonia entre as classes e o governo, entre empregados e empregadores, criação de um melhor clima de paz nacional.' (Vida Industrial, FIEMG, 1963, p. 6).

A partir desse trecho é possível apontar que o economista percebia a dificuldade que seria enfrentar a oposição de empresários e trabalhadores para implementar as medidas do Plano, que de fato não obtiveram sucesso em vista desse conflito distributivo.

A conferência de encerramento do Fórum foi realizada por Magalhães Pinto, então governador de Minas Gerais.Vale o destaque para a apresentação realizada pelo presidente da FIEMG, Fábio de Araújo Motta. Antecedendo o governador na exposição, afirmava que

Livres de quaisquer paixões, temos batido, os industriais de Minas, por soluções legítimas e urgentes para os problemas que afligem todas as classes. Mas, devemos afirmar temos nos oposto com toda a tenacidade às soluções inspiradas em postulados espúrios e danosos às liberdades humanas. (Vida Industrial, FIEMG, 1963, p. 20)

Em que pese o fator das posições de Celso Furtado e de João Goulart reconhecidas pelo empresariado, a proposição das medidas reformistas é interpretada e reduzida a "paixões", criando uma falsa dicotomia entre uma posição técnica e não ideológica com uma posição "apaixonada", "demagógica" e "populista".

Continua o empresário,

Apoiamos Senhor Governador, e isto reiteradas vezes afirmamos, todas as reformas sociais, há muito preconizadas pelo povo desde que orientadas no pensamento basilar que adotamos como lema deste Fórum: desenvolvimento econômico com justiça social dentro do regime da livre iniciativa. Julgamos, todavia, Senhor Governador, urgente e inadiável transformar a mentalidade reformista em reformas de consciências, para depois, dentro dos postulados das liberdades executar as reformas denominadas de base. (Vida Industrial, FIEMG, 1963, p. 20)

Destacamos, assim, dois aspectos: o primeiro é definição vaga e superficial do que deveriam ser as reformas, na tentativa de contrapor as reformas 
que foram colocadas pelo Plano; o segundo elemento, e mais importante, a tendência à universalização da concepção da modernização da Nação por meio da industrialização, como objetivo a ser assumido por todas as classes e pelos aparelhos de Estado. O discurso empresarial expõe tal concepção como a forma civilizadora, capaz de superar o pauperismo e elevar as condições de vida (Delgado, 1997).

Quando a edição sobre o Fórum Político foi lançada, Celso Furtado já havia deixado a função de ministro, o Ministério do Planejamento havia sido extinto e o Plano Trienal abandonado. Com o abandono do Plano, abandonou-se o último programa de estabilização econômica do governo João Goulart, e o presidente se voltaria para as reformas de base (Ferreira, 2011).

Acrescentamos que o papel atribuído pelo empresariado aos aparelhos de Estado o revestia de atuação suplementar, isto é, participar em áreas em que a iniciativa privada fosse incapaz ou desinteressada em empreender, além da recusa sistemática à regulação estatal, como na questão dos preços (Delgado, 1997).

Nesse sentido, nossas considerações principais convergem para o que identificamos como a ambiguidade do planejamento: o empresariado assumiu uma postura contrária ao Plano pelo seu aspecto restritivo, em que pese uma visão de que sua proposta fosse reguladora, ao passo que o programa elaborado por Celso Furtado também consistia em solucionar entraves da economia nacional, como a capacidade de integração e infraestrutura, questão que o empresariado reconhecia no Estado, mas que por sua abordagem heterodoxa - em "distribuir sacrificios" na contenção inicial dos ganhos reais tanto de empregados quanto de empregadores - ensejava a desconfiança dos industriais.

Entre os pronunciamentos de outras autoridades no Fórum, nos concentraremos no que foi exposto por Magalhães Pinto, da União Democrática Nacional (UDN), responsável pela mesa de encerramento desse fórum. $O$ título da reportagem sobre a sua fala é " $A$ iniciativa privada não deve sofrer cerceamento". Apesar de qualquer sugestão inicial que o título pode dar, a fala do governador foi ponderada, equilibrando o peso da liberdade econômica advogada pelos industriais ao peso das reformas propostas pelo governo no contexto da execução do Plano Trienal:

Trago-vos uma palavra de fé. O Brasil dispõe de todas as condições para progredir. Não há problema nacional que não possa ser resolvido com bom senso e espírito público. As reformas de base se farão em clima democrático, compreendendo cada um que seu 
direito vai até onde começa o direito de outrem. As riquezas podem ser dinamizadas em benefício da comunidade. Não deve sofrer cerceamentos a iniciativa privada, que promove o desenvolvimento do país. Creio que a mentalidade do lucro fácil pode ser transformada na consciência do lucro estável, razoável e justo. (Vida Industrial, FIEMG, 1963, p. 21)

Por meio do trecho, observa-se uma estratégia equilibrada em meio a interlocutores que estão representados junto à ideia de modernização pela indústria sob o regime da livre empresa, mas em um país que necessita um novo impulso no desenvolvimento econômico e diversificação produtiva com as reformas estruturais e com as reformas de base. Como destacava:

A reforma agrária é hoje reclamada como condição fundamental à própria expansão industrial, pelos efeitos que desencadeia na criação de novos mercados consumidores ou na ampliação dos mercados existentes. Não deve ser compreendida como instrumento de espoliação da propriedade, mas como processo de ampliação do acesso à terra ao maior número de brasileiros. (Vida Industrial, FIEMG, 1963, p. 21)

Esta posição sobre as reformas de base acompanhava o cuidado quanto aos riscos de uma crise e agitação social. Por outro lado, a vinculação de Magalhães Pinto aos setores industriais e comerciais desde os anos 1930 seguia com algum vigor em sua defesa da modernização pela industrialização, bem como no seguinte trecho:

O governador dos mineiros considerou a sua formação cristã e democrática tanto na vida particular como na profissional, não deixando de mencionar sua entrada na vida pública: "Por assinar o Manifesto dos Mineiros, perdi o cargo de Diretor do Banco, que a duras penas havia conquistado após longos anos de trabalho, atravessando jornadas de 18 a 20 horas. Foi um ato consciente e pensado, em que riscos e os prejuízos diante do objetivo maior que era a reconquista democrática. Foi assim que entrei na vida pública e nela permaneço, lutando pela prevalência da vontade popular, pela livre escolha dos dirigentes e, sobretudo, pela discussão". (Vida Industrial, FIEMG, 1963, p. 21)

O governador referia-se a um episódio de 1943, quando foi afastado pelo então interventor mineiro (cargo equivalente ao de governador do estado) Benedito Valadares, por ser um dos signatários do Manifesto dos Mineiros, documento crítico feito por 92 representantes de setores civis exigindo a reaber- 
tura democrática no Estado Novo. Inclusive, muitos participantes tornaram-se fundadores da União Democrática Nacional (UDN) e do Partido Social Democrático (PSD) no estado. ${ }^{7}$

O governador encerrava sua participação, segundo a revista, rearticulando a paz social e progresso pelo desenvolvimento para o "destino" que estaria reservado à "Pátria", buscando seu sentido, inclusive, no passado colonial:

Herdeiros da coragem, da fibra e do espírito viril dos descobridores, dos pioneiros, dos sonhadores e dos inconfidentes, acreditamos na força do trabalho e na vitória das lutas estéreis e as divergências ocasionais, caminhemos juntos, de mãos dadas, sem qualquer discriminação, pela estrada ensolarada do progresso, que levará nossa Pátria ao seu grande destino. Tenhamos fé no Brasil. (Vida Industrial, FIEMG, 1963, p. 21)

O "destino" encontrado no "progresso" tem seu sentido afirmado no passado pela "coragem" e pelo "pioneirismo", que, no presente, àquela altura, eram consubstanciados na redescoberta do desenvolvimento da Nação a partir da liderança do setor industrial e no papel dos sujeitos que capitaneariam tal processo.

Ademais, a estratégia adotada pelos industriais mineiros foi a de criar dicotomias entre a proposta de desenvolvimento contida no Plano Trienal com a reivindicada em seu discurso de industrialização como redenção da Nação, inserida no contexto de rejeição à "demagogia" e ao "populismo" que atribuíam às posturas de João Goulart e Celso Furtado. Justificava essa postura o reforço dos laços dos aparelhos de Estado com as massas populares em um momento de intenso conflito distributivo, que se aliava às reformas, chamadas de base, contidas no programa, e que, de um lado, se propunham a uma racionalização da ação governamental (bancária e administrativa) e, por outro lado, à eliminação de entraves institucionais à otimização dos fatores de produção (fiscal e agrária) (Brasil, 2011).

Portanto, o binômio criado entre o dirigismo reconhecido, pelos industriais, na planificação econômica em contraposição ao desenvolvimento sob regime da livre empresa, defendido pelos mesmos industriais, criou uma leitura ambígua entre a solução dos entraves estruturais e o liberalismo como reserva

\footnotetext{
${ }^{7}$ A respeito de sua biografia, vide o verbete "José de Magalhães Pinto", disponível em: < goo.gl/kvauzA $>$. Acesso em: 30 nov. 2017.
} 
ideológica, tensionado em um momento de intenso conflito entre os ganhos de produção e os ganhos salariais.

\section{3. "Da vigília cívica à advertência na vitória": os industriais mineiros, a radicalização política e a solução autoritária}

Até este ponto deste artigo apontamos as relações estabelecidas entre a política econômica e as frentes partidárias com o empresariado industrial mineiro por meio da revista Vida Industrial. Para o tópico final deste artigo, nosso desafio consiste em compreender como os industriais legitimaram a ruptura institucional e a deposição do presidente João Goulart por meio de um golpe civil-militar. Para isso, nos embasaremos no "caminho da radicalização" e no isolamento presidencial a partir da segunda metade de 1963, procurando compreender como se erguera a "voz" empresarial em reação ao governo Jango.

Com o malogro do Plano Trienal traduzido nas saídas de Celso Furtado e San Tiago Dantas dos ministérios do Planejamento e da Fazenda, respectivamente, ${ }^{8}$ ficou a cargo de Carvalho Pinto a pasta da Fazenda. O nome conservador tinha a intenção de manter um elo entre o governo Goulart e os setores empresariais (Ferreira,2013). No campo social e político, a situação tornou-se muito delicada.

Felipe Pereira Loureiro (2012) observa que o segundo semestre de 1963 constitui-se como um período de estopim de muitos movimentos grevistas, como a greve dos bancários, a greve dos enfermeiros de Santos, a greve dos 700 mil em São Paulo e, no caso mineiro, a greve da Usiminas em Ipatinga com o trágico desfecho no assassinato de 30 operários grevistas no episódio que ficou conhecido como "massacre de Ipatinga". As estratégias do governo Goulart consistiram em estabelecer concessões aos grevistas pelo aumento salarial, ao mesmo passo em que se tentava firmar algum tipo de influência mais direta sobre a sua direção, o que se tornava muito difícil em um momento em que o empresariado via na repressão ao movimento sindical um caminho para a estabilidade (Loureiro, 2012).

Diante desse contexto apresentado, a edição de agosto/outubro de 1963 trazia, em substituição ao editorial, um manifesto das classes patronais mineiras

\footnotetext{
${ }^{8}$ O Ministério do Planejamento foi extinto e Celso Furtado retornou à direção da SUDENE. Enquanto San Tiago Dantas voltou ao cargo de deputado federal.
} 
endereçado aos poderes da República, com o título "Classes produtoras condenam o sindicalismo subversivo", assinado pelos seguintes representantes: Fábio de Araújo Motta (Federação das Indústrias do Estado de Minas Gerais), Exaltino José Marques Andrade (Federação do Comércio do Estado de Minas Gerais), Miguel Augusto Gonçalves de Souza (Associação Comercial de Minas Gerais), Waldir Soeiro Emrich (Centro das Indústrias da Cidade Industrial), Geraldo Saturnino (Sociedade Mineira de Agricultura), Cássio França (Clube dos Diretores Lojistas de Belo Horizonte), Sinval Ladeira Neves (União dos Varejistas de Minas Gerais), Antônio Vidigal (Associação Mineira de Farmacêuticos), Lauro Ferreira (Sociedade Mineira de Engenheiros), José Cavalini (Associação Brasileira de Lavanderias e Tinturarias), Ruy de Castro Magalhães (Sindicato dos Bancos de Minas Gerais) e Josaphá Macedo (Federação das Associações Rurais do Estado de Minas Gerais).

De início, o Manifesto condenava a "inflação desenfreada", a "indisciplina", as "espúrias organizações" e o "sindicalismo revolucionário", reclamando que estava faltando à República "o princípio da autoridade" para se evitar os atentados à Constituição. A argumentação empresarial visava amalgamar a explicação da crise social ao mesmo processo da crise econômica, deixando claro que havia um perigo revolucionário da ausência do poder central. Como demonstra o seguinte trecho:

Essa condescendência avilta o poder político e traz o mais seguro caldo de cultura à desorganização econômico-financeira pródromo da desordem social e das soluções revolucionárias. Já aí está a inflação quase incontrolável, inutilizando os melhores esforços, com a estarrecedora expectativa de grande crescimento demográfico, paralelamente a um decréscimo da taxa de desenvolvimento. É preciso pôr um paradeiro à agitação organizada, impõe-se a restauração do princípio de autoridade para que novamente impere a ordem e se possibilite o progresso [...] Minas Gerais não pode ver o desenvolvimento da crise em que se debate o país, sem essa advertência aos responsáveis pela condução da sua vida política para que não se deixem levar pelas aspirações das paixões e interesses momentâneos, mas antes se orientem pelos supremos objetivos da Nação, com os quais se harmonizam as soluções ditadas pelo equilíbrio que põe o mais grave senso da ordem. (Vida Industrial, FIEMG, 1963, p. 2)

Percebe-se uma relação de compromisso sendo estabelecida entre a "ordem" e o "progresso" do país. Por "agitação organizada" se compreendia a ação sindicalista, que se efetivava por meio da "condescendência avilta o 
poder político", que sem o "princípio da autoridade", o progresso nacional estava inviabilizado. Além disso, atentemo-nos para a resolução do texto: Minas deveria garantir o desenvolvimento da Nação, por meio da harmonia, equilíbrio e senso de ordem. Reclama-se o sentimento de mineiridade sendo elemento utilizado e empregado nesse contexto, reconhecido no apego à ordem e ao equilíbrio (Dulci, 1999). Além disso, ainda se conclamava a participação de outros setores nessa tomada de posição. ${ }^{9}$

Na mesma edição que trazia o Manifesto das Classes Produtoras, a fala de Fábio de Araújo Motta junto aos industriais de São Paulo era reportada, sob o título "Precisamos de reformas de caráter e de paz alicerçada na decência". $O$ industrial defendia que o empresariado não se constituía enquanto um grupo de reacionários, de tal maneira que defendia a classe manifestando seu apoio à legislação trabalhista e à transição do regime parlamentarista para o regime presidencialista.Todavia, alertava o poder federal que o país estava em estagnação econômica havia dois anos, com crises e colapso do desenvolvimento. Chamava a atenção para a necessidade de reformas, porém, "não as de base, mas as grandes reformas que estão para ser feitas neste país", entendendo o dirigente que não se tratava de uma "cruzada anticomunista", mas sim da exigência diante do governo de incentivo à industrialização, "para que haja mais oportunidade, mais riquezas, mais empregos" (Vida Industrial, FIEMG, 1963, p. 33).

O argumento sobre a crise foi estabelecido, por Motta, em elementos que se fundem em uma relação causal que dão sentido à industrialização em oposição à estagnação. $O$ primeiro foi traduzido nas reformas de caráter, indicadas de forma imprecisa pelo autor. Entendemos, todavia, pelo contexto de seu uso, que se trata de um afastamento de posições entendidas como sendo "ideologias apaixonadas" e sem vinculação com o progresso econômico, dadas as críticas recorrentes produzidas pelos que as entendiam como comunistas. A estagnação aparece relacionada a esse fator, e o uso de antinomias é um aspecto importante de sua construção argumentativa. Como também vimos ao tratar da execução do Plano Trienal, o empresário justificava sua posição em oposição ao que entendia ser um caráter demagógico da administração, ao passo que nessa fala Motta tem como objetivo denunciar a falta de autoridade e a "infiltração ideológica" como fatores que causariam

\footnotetext{
${ }^{9}$ Citando um trabalho de Hélio Silva (1975), Jorge Ferreira (2013) aponta que após a tentativa da deflagração do estado de sítio, Magalhães Pinto dobrou o efetivo da Polícia Militar, chegando a vinte mil homens bem municiados e com eficientes meios de transporte.
} 
a estagnação do progresso. Seus criticados não estariam, dessa forma, comprometidos com o sentido da industrialização.

Em janeiro de 1964, a FIEMG realizou mais uma vez a eleição para sua diretoria, sendo que Fábio de Araújo Motta acabou reeleito por unanimidade para o mandato de mais dois anos à frente da entidade. A edição do editorial saudava o industrial, trazendo abaixo do corpo do texto uma figura altiva de seu presidente, encetando uma narrativa de liderança e autoridade sobre sua imagem. A tomada de posição, cada vez mais evidente, era ratificada pelo pleito, de tal maneira que:

A unanimidade significa, ainda, a coesão e união de classe, no momento exato em que essa união e essa coesão se tornam mais necessárias. A ninguém é lícito desconhecer que vivemos dentro de um clima de agitação e insegurança, dentro do qual forças desagregadoras agem sem a menor cerimônia, perturbando a ordem e agitando o país. Nessa hora, quando parece que nos encaminhamos para a convulsão, torna-se absolutamente necessária a união e coesão das forças produtivas e democráticas, quando as mesmas de colocam em posição de defesa das instituições livres. (Vida Industrial, FIEMG, 1964, p. 2)

Em alguma medida, podemos afirmar que o elemento mais enfatizado por este artigo se expressa - declarada e efetivamente - neste momento: o consenso empresarial. Eleger com unanimidade Fábio Motta consistiu em pleitear por um determinado projeto, expresso na defesa da posição dos empresários em meio ao conflito distributivo, o confronto direto aos movimentos reconhecidos no Comando Geral dos Trabalhadores (CGT) e na União Nacional dos Estudantes (UNE) no campo social, enquanto no campo político o temor crescia com relação à Frente de Mobilização Popular (FMP), liderada pelo então deputado federal do estado da Guanabara, Leonel Brizola.

Alguns episódios ocorridos entre dezembro de 1963 e março de 1964 servem para a melhor compreensão da tomada de decisão verificada anteriormente. Como já apontamos antes, Carvalho Pinto era um elemento fundamental de ligação entre o governo Goulart e o empresariado. Não é pouco significativo que, em meio às medidas nacionalistas e de ampliação de benefícios sociais tomados pela administração, em 20 de dezembro, diante de ataques vindos de movimentos sociais de esquerdas e da FPM, o ministro da Fazenda tenha renunciado ao cargo. Àquela altura, João Goulart havia nomeado o almirante Aragão - próximo de Brizola - para o comando do 
Corpo de Fuzileiros Navais, em desagrado aos oficiais da Marinha. Benefícios da Previdência Social foram estendidos aos trabalhadores rurais, empresas com mais de cem funcionários deveriam garantir-lhes ensino gratuito, concedeu-se o $13^{\circ}$ salário ao funcionalismo público e foram revistas concessões de exploração de jazidas minerais em Minas Gerais (Ferreira, 2013).

Em 24 de dezembro, o presidente decretou o monopólio da Petrobrás na importação de petróleo e derivados, contrariando interesses estadunidenses. Depois, em 17 de janeiro, quando regulamentou a remessa de lucros para o exterior, o "pavor" empresarial cresceu com os rumores de que o monopólio do câmbio seria assinado em breve (Ferreira, 2013).

Mais do que apenas demarcar uma posição na política econômica, Goulart preocupava-se com o agravamento da crise, com as sucessivas "recuadas" dos credores externos ao refinanciamento da dívida externa, deliberadamente para tencionar o malogro da administração e das reformas de base. O presidente chegou em fins de fevereiro com poucas opções, dentre as poucas que lhe restavam, optou por "aliar-se às esquerdas, acreditar nas forças que elas diziam dispor" e "partir para a radicalização e o embate" (Ferreira, 2013, p. 381)

Do ponto de vista empresarial, o diálogo com o governo João Goulart havia sido rompido definitivamente e sua posição - antes vista como vacilante - já havia se transformado em enfrentamento, inviabilizando sua própria tolerância. A revista atingia o seu efeito. A classe estava organizada.

Ainda de acordo com Jorge Ferreira, os episódios de anistia de João Goulart à revolta dos subalternos da Marinha de Guerra e ao almirante Aragão no episódio de confronto com o alto oficialato da Marinha foram recebidos como uma ofensa à integridade do conjunto de valores, ideias e códigos comportamentais das forças armadas servindo como estopim para o levante dos oficiais militares contra o presidente. $\mathrm{O}$ seu discurso exaltado na cerimônia de posse da diretoria da Associação dos Sargentos em 30 de março foi o argumento final para a resposta dos setores sociais de oposição a João Goulart apoiarem sua deposição (Ferreira, 2013).

Com o apoio de Magalhães Pinto, as tropas do general Olímpio Mourão Filho se deslocaram de Juiz de Fora para a Guanabara. Goulart soubera dessa informação na tarde do dia 31 de março, estava determinado a arrasar com o governador mineiro, mas a informação cedida por San Tiago Dantas de que os Estados Unidos estavam com um porta aviões se aproximando da costa do Rio de Janeiro fez com que Jango recuasse e tentasse obter a lealdade dos 
generais do Exército. O presidente obteve tal lealdade, principalmente, do general do III Exército, Ladário Teles, que organizou a resistência em Porto Alegre junto com Leonel Brizola e com o almirante da Marinha, Cândido Aragão, que esperava ordens para prender Carlos Lacerda. Novamente foi informado por San Tiago Dantas de que se a prisão de Lacerda acontecesse, as tropas estadunidenses invadiriam o território nacional.A ação também tinha se voltado para a desarticulação dos movimentos de esquerda, de modo que o CGT e a UNE sofreram ataques (Ferreira, 2013).

Em $1^{\circ}$ de abril, tendo se deslocado inicialmente para Brasília (onde fez um manifesto à Nação denunciando o golpe e a reação às reformas de base e à democratização da sociedade) e depois para Porto Alegre (onde Brizola e o general Teles tentaram convencê-lo a resistir), Jango já se dava conta de que a resistência estava desarticulada e insistir nela seria o início de uma guerra civil. Ao avaliar a situação, percebera que não se tratava de um movimento popular, mas sim de uma coalizão civil-militar com o apoio de forças estrangeiras. Naquele momento, o governo trabalhista, a sociedade brasileira e os apoiadores da deposição de Goulart não perceberam que em 1964 havia se configurado um novo tipo de golpe (Ferreira, 2013).

Enquanto grupo vitorioso nesse processo, os industriais mineiros lançaram um editorial explícito de vitória na derrubada do governo trabalhista, intitulado "Da vigília cívica à advertência na vitória", do qual nos vale o destaque de boa parte do texto:

Em nenhum momento, as Classes produtoras de Minas Gerais estiveram ausentes da vida pública brasileira. Com o mesmo espírito de 1946, quando da ratificação da "Carta da Paz", ficaram alertas na defesa das instituições e liberdades democráticas, dentro de uma coesão perfeita e operante.Já em setembro de 1963, quando o perigo da infiltração vermelha tornava-se mais alarmante, os homens de empresa deram seu grito de liberdade e advertência, num documento em que mostrava aos Poderes da República a ameaça vinda do sindicalismo revolucionário [...] Prosseguindo dentro do plano de união das Classes Produtoras em prol da defesa de seus interesses quanto à livre empresa e incremento da livre iniciativa e ainda dos direitos assegurados pela Constituição e princípios democráticos aliados às tradições cívicas e cristãs do povo brasileiro, a Federação das Indústrias passou a se reunir, semanalmente às sextas-feiras. Estes encontros, em que cada homem de indústria procurava trazer mais outro companheiro do ramo até se ter a presença de todos os grupos expressivos a produção mineira, 
receberam o nome de "Semanais" e passaram a constituir uma das preocupações dos homens de empresa liderados por Fábio de Araújo Motta e seus companheiros na direção. Era a união em prol de uma causa nacional. A Federação das Indústrias do Estado de Minas Gerais e o Centro das Indústrias de Minas Gerais, no instante em que se concretiza a vitória de mais um movimento mineiro pela preservação da democracia e pelo respeito aos princípios constitucionais, dirigem-se aos homens de empresa e à coletividade industriária, expressando seu júbilo pela retomada do ritmo de ordem e trabalho que assegura o processo de nosso desenvolvimento econômico. (Vida Industrial, FIEMG, 1964, p. 2)

Completou-se um sentido. A superação do Estado Novo foi justificada pela atuação dos setores do empresariado, materializada na Carta da Paz, dando-se relevância a coesão entre a classe como elemento fundamental para agência política dos setores patronais. A importância do consenso de classe foi recuperada no Manifesto das Classes Produtoras, como foi também o caso dos "Semanais", portanto estava estabelecido o sentido histórico interpretado pelos industriais, tendo seu efeito no "movimento democrático". A classe não só estava organizada, como fazia sua propaganda para isso, demostrando sua capacidade de agência política. Podemos pensar que a revista, como uma publicação feita por empresários e para empresários, mostrava seu potencial de efeito.Também é notável que tenha havido uma mensagem para o futuro: a partir da lição dada pelo passado e pelo presente, existiu um chamado para a necessidade do consenso empresarial de que as pautas requeridas pela classe não estarão dadas e muito menos serão prontamente resolvidas, elas só serão representadas e postas em prática se tiverem paralelamente a coesão das classes produtoras.

$\mathrm{Na}$ leitura dos industriais, a crise justificava o apego ao liberalismo enquanto reserva ideológica e a posição vacilante exigia coesão empresarial, evitando que o empresariado estivesse "ausente da vida pública brasileira". A "vigília cívica" traduziu-se em reação. O consenso formado por meio de espaços e discursos foi útil à ação, na medida em que o caminho da radicalização "exigiu" do empresariado uma tomada de posição diante da tomada de posição do governo trabalhista. A conciliação se esgotou, os projetos antagônicos, defendidos nas antinomias argumentativas baseadas em "desenvolvimento" e "atraso", não poderiam coexistir.

Com a ruptura institucional deflagrada em $1^{\circ}$ de abril de 1964 , abriu-se um caminho para uma nova experiência. A matéria de destaque à posse 
do marechal Castelo Branco em 15 de abril parece consolidar a coesão de classe vinculada a um projeto político: "Estado não será estorvo à iniciativa privada" (Vida Industrial, FIEMG, 1964, p. 7).

O golpe civil-militar encerrou o governo João Goulart, a política trabalhista e a experiência democrática após o Estado Novo, levando aos aparelhos do Estado um projeto político autoritário dirigido pelos militares com apoio de setores civis. Em um primeiro momento, traduzido nas medidas de austeridade fiscal e arrocho salarial e, a partir de 1968, na modernização conservadora, expressa nas medidas industrialistas. Estava aberto um novo momento na República e com ele um novo desafio para a organização de classe. E saber como se vincular em torno de um projeto de Nação exigiria o debate dos industriais sobre as estratégias para novos ou velhos consensos.

\section{Considerações finais}

Como vimos, as relações entre política econômica e reivindicações da indústria demonstraram a importância tecnocrática na estruturação da Federação, o que implica considerarmos a justificativa técnica das relações entre os industriais e os aparelhos de governo, não obstante tenham ficado expressos os níveis de tensão entre os projetos que estavam se enfrentando. Isso nos leva a considerar o desenvolvimento para além de um processo ou de uma condição para o crescimento do produto interno bruto, mas como um conceito em disputa.

Foi nesse esforço por um papel ativo enquanto agente político e social que se concentrou a reflexão final, de tal maneira que nos perguntamos como se justificou o apoio ao desfecho autoritário que depôs o governo de João Goulart.Tomamos dois elementos importantes: a argumentação retórica para conduzir a um efeito e uma "atribuição de sentido", ou seja, enquanto articulação do tempo histórico.

É justamente nesses dois elementos que residem pontos fundamentais para os resultados da nossa pesquisa. $\mathrm{O}$ consenso de classe não estava dado e construído para as tomadas de posição, fossem aquelas relacionadas às medidas econômicas entre 1961 e 1964 ou em relação ao golpe civil-militar. O posicionamento de classe foi sendo pavimentado pela construção de um entendimento em comum que usava a revista como meio privilegiado para sua 
veiculação: a necessidade de orientar a política econômica a favor dos investimentos privados, a atenção com o desenvolvimento regional e a urgência em conter a ação do sindicalismo operário são pontos de orientação para a coesão de classe.

Com a intenção de produzir efeito, entendemos que a construção do consenso se deu por atribuir uma importância à ação entre o próprio empresariado. Ou seja, empregar a revista como uma mediação de posições que deveriam ser assumidas numa interlocução entre seus editores e seus leitores, dando argumentos que defenderam a FIEMG como representante legítima do empresariado, que não se resume a "interesses de classe", mas que intencionava à solução da crise a partir de um modelo de desenvolvimento que privilegiasse a indústria como protagonista.

A atribuição de sentido empregou o passado como uma forma de lição: o empresariado não poderia se furtar a participar ativamente da definição dos rumos do país como fizera em outros momentos. O presente, naquela ocasião, colocava à prova a classe, o consenso era o ponto central para que o empresariado visse seus objetivos bem-sucedidos no desfecho de março e abril de 1964.

Enquanto articulação do tempo histórico, interpretamos que o papel no passado contido na Carta da Paz na transição do fim do Estado Novo para a experiência democrática foi retomada como uma substância elementar para o empresariado: a vigília cívica. Com a derrubada de João Goulart e o fim da experiência democrática, a ruptura institucional marcou a abertura de um novo período na história republicana do Brasil.

Nesse sentido, o empresariado precisaria mobilizar estratégias para reafirmar ou fundar consensos. Como estabelecer o vínculo entre a "vigília cívica" e a modernização conservadora que marcaria os anos do regime foi o desafio aberto para os industriais a partir de 1964.

\section{Referências}

BAER, W. A industrialização e o desenvolvimento econômico do Brasil. Rio de Janeiro: Fundação Getúlio Vargas, 1979.

BASTOS, P. P. Z. O Plano Trienal e sua economia política. In: d'AGUIAR, Rosa Freire (Org.). O plano trienal e o ministério do planejamento. Rio de Janeiro: Contraponto: Centro Internacional Celso Furtado, p. 441-450, 2011. 
BIELSCHOWSKY, R. Pensamento econômico brasileiro: o ciclo ideológico do desenvolvimentismo. Rio de Janeiro: Contraponto, 2000.

BRASIL. Presidência da República. Plano trienal de desenvolvimento econômico e social: 1963-1965. In: AGUIAR, Rosa Freire d' (Org.). O plano trienal e o ministério do planejamento. Rio de Janeiro: Contraponto; Centro Internacional Celso Furtado, p. 35-440, 2011.

COLISTETE, R. P. Salários, produtividade e lucros na indústria brasileira, 1945-1979. Revista de Economia Política, v. 29, n. 4, p. 1-23, out. 2009.

DELGADO, I. G. A estratégia de um revés: Estado e associações empresariais em Minas. Juiz de Fora: EDUFJF, 1997.

DINIZ, C. C. Estado e capital estrangeiro na industrialização mineira. Belo Horizonte: UFMG/PROED, 1981.

DULCI, O. S. Política e recuperação econômica em Minas Gerais. Belo Horizonte: EDUFMG, 1999.

EAKIN, M. Tropical capitalism: the industrialization of Belo Horizonte, Brazil. New York, Palgrave, 2001.

FERREIRA, J. O governo João Goulart e o golpe civil-militar de 1964. In: FERREIRA, Jorge; DELGADO, Lucília de Almeida Neves (Org.). O Brasil Republicano. O tempo da experiência democrática: da democratização de 1945 ao golpe civil- militar de 1964. Rio de Janeiro: Civilização Brasileira, p. 343-404, 2013.

FERREIRA, J.João Goulart: uma biografia. Rio de Janeiro: Civilização Brasileira, 2011.

LOUREIRO, F. Empresários, trabalhadores e grupos de interesse: a política econômica nos governos Jânio Quadros e João Goulart, 1961-1964. São Paulo: USP, 2012 (Tese de Doutorado em História Econômica).

MELLO, J. M. C. de. O capitalismo tardio. São Paulo: Editora UNESP; Campinas: FACAMP, 2009. 
VIANNA, J.A. de. Banco do Desenvolvimento, justificativa e repercussão na economia mineira. Vida Industrial, Belo Horizonte, ano 9, n. 1, p. 24-29, nov. 1961.

VIDA INDUSTRIAL, FIEMG. Celso Furtado: "Plano Trienal não é revolucionário nem audacioso”. Vida Industrial, Belo Horizonte, ano 10, p. 6, abr./ jul. 1963.

VIDA INDUSTRIAL, FIEMG. Classes produtoras condenam o sindicalismo subversivo. Vida Industrial, Belo Horizonte, ano 10, p. 2, ago./out. 1963.

VIDA INDUSTRIAL, FIEMG. Com a palavra o presidente. Vida Industrial, Belo Horizonte, ano 9, n. 1, p. 2, nov. 1961.

VIDA INDUSTRIAL, FIEMG. Da vigília cívica à advertência na vitória. Vida Industrial, Belo Horizonte, ano 11, p. 2, mar./abr. 1964.

VIDA INDUSTRIAL, FIEMG. Editorial. Vida Industrial, Belo Horizonte, ano 9, n. 5, p. 2, nov. 1962.

VIDA INDUSTRIAL, FIEMG. Editorial. Vida Industrial, Belo Horizonte, ano 10, p. 2, abr./jul. 1963.

VIDA INDUSTRIAL, FIEMG. Editorial. Vida Industrial, Belo Horizonte, ano 11, p. 2, jan./fev. 1964.

VIDA INDUSTRIAL, FIEMG. Encontro dos governadores, reivindicações da indústria. Vida Industrial, Belo Horizonte, ano 9, n. 2, p. 2, dez. 1961.

VIDA INDUSTRIAL, FIEMG. Magalhães Pinto encerrou o Fórum: "Iniciativa privada não deve sofrer cerceamento". Vida Industrial, Belo Horizonte, ano 10, p. 27-28, abr./jul. 1963.

VIDA INDUSTRIAL, FIEMG. Precisamos de reformas de caráter e de paz alicerçada na decência. Vida Industrial, Belo Horizonte, ano 10, p. 33, ago./ out. 1963. 
VIDA INDUSTRIAL, FIEMG. Presidente Castelo Branco:"Estado não será estorvo à iniciativa privada". Vida Industrial, Belo Horizonte, ano 11, p. 7 , mar./abr. 1964.

VIVACQUA, G. Planejamento, políticas partidárias e administração. Vida Industrial, Belo Horizonte, ano 10, p. 17, fev./mar. 1963. 